\title{
Haemodialysis in the treatment of lactic acidosis associated with acute hepatic and renal failure
}

A. ColombI
M.D.

\author{
H. THÖLEN \\ M.D.
}

\section{Medical Department of the University of Basel (Switzerland)}

\begin{abstract}
Approximately one third of endogenous lactate is normally metabolized in the liver. In acute liver failure, accumulation of non-metabolized pyruvate and lactate results in high blood pyruvate and lactate levels (Thölen et al., 1966). Often in this condition it is possible to control the arterial $\mathrm{pH}$ by the administration of sodium bicarbonate or THAM; if however there is also renal failure or marked secondary aldosteronism, the administration of large amounts of sodium and fluid is limited. Under these circumstances, haemodialysis offers a means of correcting the acidosis without increase of extracellular volume and with removal of lactate.
\end{abstract}

\section{Case report}

A. H. P., a 31-year-old cook was admitted to a district hospital with severe dyspnoea at rest. This had started suddenly after 8 days of abnormal fatigue. The patient was known to drink eight to ten bottles of beer daily. Hyperventilation and cyanosis of the lips were observed in the absence of pulmonary findings. The patient was jaundiced with a large liver $7 \mathrm{~cm}$ below the ribs. The blood pressure was $140 / 60 \mathrm{mmHg}$, pulse rate $96 / \mathrm{min}$. Serum glutaminpyruvate-transaminase (SGPT) was 870 WU (Wroblenski), prothrombin-time was $15 \%$ (Quick). The following day the blood pressure (BP) fell to 70/0 $\mathrm{mmHg}$ and could not be corrected by administration of Dextran, angiotensin II and $200 \mathrm{mg}$ hydrocortisone i.v. The patient was then transferred to the Medical Department of the University of Basel.

On admission, the patient was drowsy and confused, but responded to simple commands. Hyperventilation, peripheral cyanosis and ankle oedema were present and at both pulmonary bases now there were crepitations. Central venous pressure (CVP) was $31.5 \mathrm{~cm} \mathrm{H}_{2} \mathrm{O}$ and arterial BP 85/40 $\mathrm{mmHg}$. Serum sodium was $127 \mathrm{mEq} / \mathrm{l}$ and was considered to be low because of overhydration. The patient was anuric after an excretion of $300 \mathrm{ml}$ during the previous $24 \mathrm{hr}$. Blood urea was $70 \mathrm{mg} /$

* II, V, VII-index, sum of blood clotting factors II, V and VII in percent. Normal value 260-300 (Colombi, 1969).

Request for reprints: Dr A Colombi, Nierenstation, Kantonsspital Lucerne, Switzerland
$100 \mathrm{ml}$, the II, V, VII-index*77, blood ammonia $202 \gamma / 100 \mathrm{ml}$ (Conway), SGOT $2400 \mathrm{WU}$ and serum bilirubin $3.2 \mathrm{mg} / 100 \mathrm{ml}$ (Schellong \& Wende) indicating a severe liver failure with impending hepatic coma. The blood pH of 6.94, $\mathrm{PaCO}_{2}$ of $15 \mathrm{mmHg}$ with a base excess exceeding $-25 \mathrm{mEq} / \mathrm{l}$ were explained by a serum lactate of $150 \mathrm{mg} / 100 \mathrm{ml}$. The electrocardiogram showed partial right bundle branch block (Fig. 1). On the chest X-ray, cardiomegaly, distension of the pulmonary veins and some patchy infiltrations were seen (Fig. 2).

A Scribner shunt was inserted into the right forearm and an 8-hr haemodialysis was performed with a Travenol RSP Dialyser using an ultraflow 100 coil. Further characteristics of this dialysis are given in Table 1.

TABLE 1. Dialysis characteristics

\begin{tabular}{ll}
\hline Dialyser type & \multicolumn{1}{c}{ Travenol RSP } \\
Coil & Ultraflow 100 \\
Blood flow & $270-320 \mathrm{ml} / \mathrm{min}$ \\
Venous pressure & $80-110 \mathrm{~mm} \mathrm{Hg}$ \\
Dialysate flow & $600 \mathrm{ml} / \mathrm{min}$ \\
Duration & $8 \mathrm{hr}$ \\
Dialysate concentration: & $132.0 \mathrm{mEq} / \mathbf{l}$ \\
$\mathrm{Na}$ & $1.3 \mathrm{mEq} / \mathrm{l}$ \\
$\mathrm{K}$ & $106.0 \mathrm{mEq} / 1$ \\
$\mathrm{Cl}$ & $1.0 \mathrm{mEq} / \mathbf{l}$ \\
$\mathrm{Mg}$ & $3.5 \mathrm{mEq} / \mathrm{l}$ \\
$\mathrm{Ca}$ & $35.0 \mathrm{mEq} / 1$ \\
Acetate & $200.0 \mathrm{mg} / 100 \mathrm{ml}$ \\
Glucose & \\
\hline
\end{tabular}

Rapid improvement of respiration, increase of arterial BP to $145 / 75 \mathrm{mmHg}$, decrease of CVP to $22 \mathrm{~cm} \mathrm{H}_{2} \mathrm{O}$, disappearance of mental confusion and a dramatic improvement in arterial blood gases, blood pH, serum lactate, serum sodium and urea were observed (Table 2) during dialysis. Because of persisting anuria, another 5-hr haemodialysis was done the next day. On the third day after admission, a diuresis started with $190 \mathrm{ml} / 24 \mathrm{hr}$ (Fig. 3). However, the most promising features of improvement were a consistent increase of the II, V, VII-index and a blood lactate keeping within normal limits. SGPT decreased from $3000 \mathrm{WU}$ to $36 \mathrm{WU}$ within 10 days. When on the fifth day after 


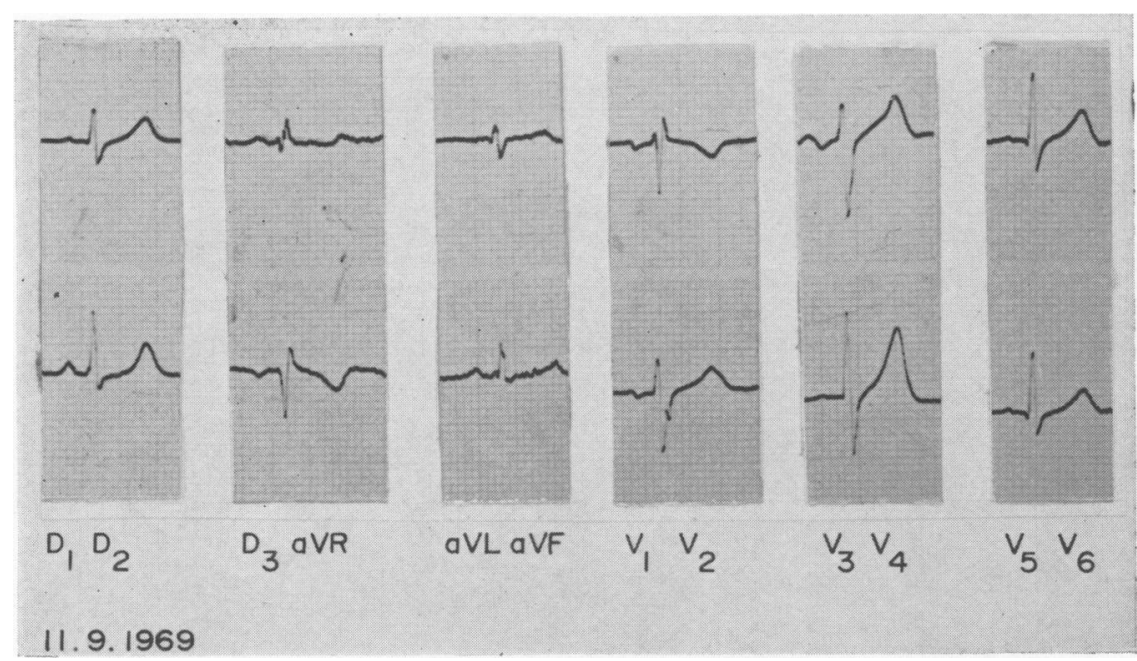

Fig. 1. Patient A. H. P., 31, electrocardiogram showing partial right bundle branch block.

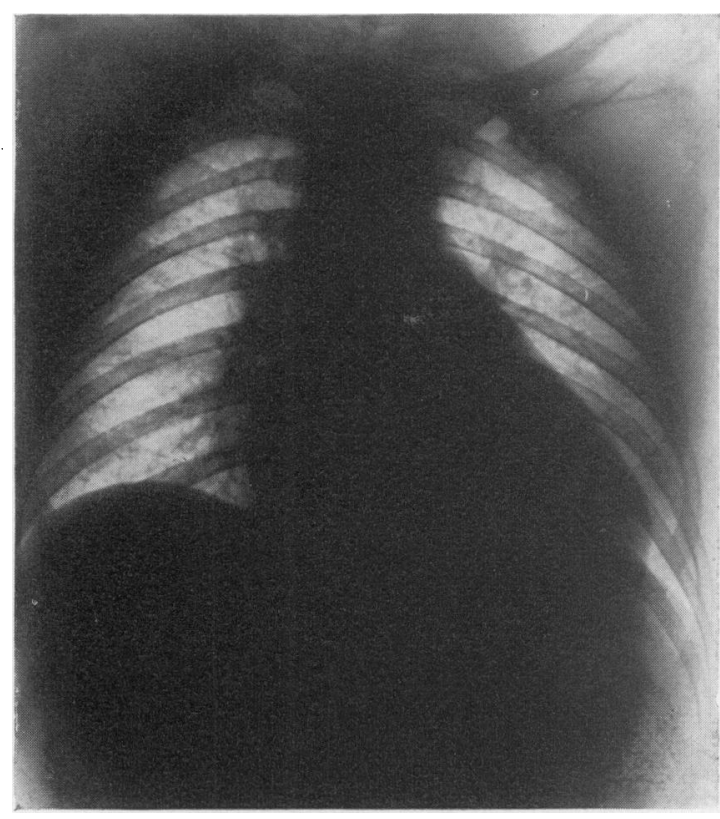

Fig. 2. Patient A. H. P., 31, chest X-ray showing cardiomegaly, distension of the pulmonary veins and some patchy infiltrations.

admission the prothrombin-time had reached $50 \%$, laparoscopy and liver biopsy were carried out. Because of large adhesions the liver surface could not be seen. The biopsy specimen showed extensive centrolobular haemorrhagic necrosis, associated with mild fatty degeneration. A repeat biopsy 18 days later showed massive regeneration. At that time the prothrombin-time was $72 \%$, SGPT $18 \mathrm{WU}$,
TABLe 2. Physical and chemical data before and after 8-hr haemodialysis for severe lactic acidosis

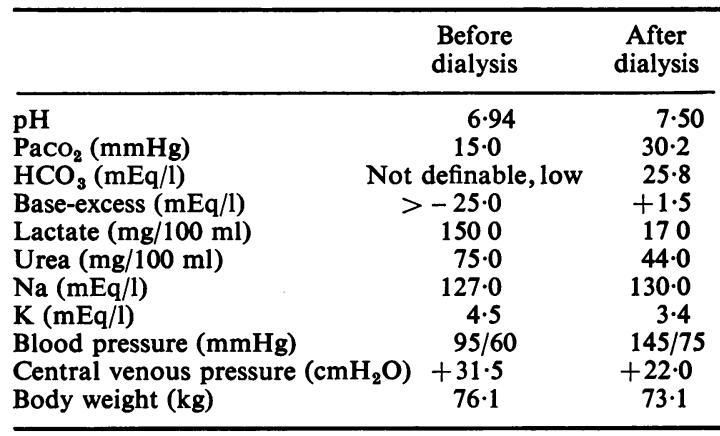

SGOT $17 \mathrm{WU}$, blood urea $17 \mathrm{mg} / 100 \mathrm{ml}$, creatinine $0.7 \mathrm{mg} / 100 \mathrm{ml}, \mathrm{C}_{\text {Inulin }} 106 \mathrm{ml} / \mathrm{min}, \mathrm{C}_{\mathrm{PAH}} 546 \mathrm{ml} / \mathrm{min}$, filtration fraction $20 \%$ and $T_{m}$ PAH $75 \mathrm{mg} / \mathrm{min}$. Chest X-ray was normal and the patient was discharged 23 days after admission.

\section{Discussion}

Correction of lactic acidosis by haemodialysis has been reported in patients with phenformin-induced lactic acidosis (Ewy et al., 1963; Maher \& Schreiner, 1967; Westervelt, 1966). Haemodialysis has not yet been recommended in the treatment of lactic acidosis occurring in acute hepatic failure. This treatment however has to be considered for the control of the severe lactic acidosis that often occurs in severe hepatic failure.

Haemodialysis as a treatment for endogenous hepatic coma has not been very successful (Trey et al., 1966). This, however, does not mean that this procedure is useless in the treatment of severe 

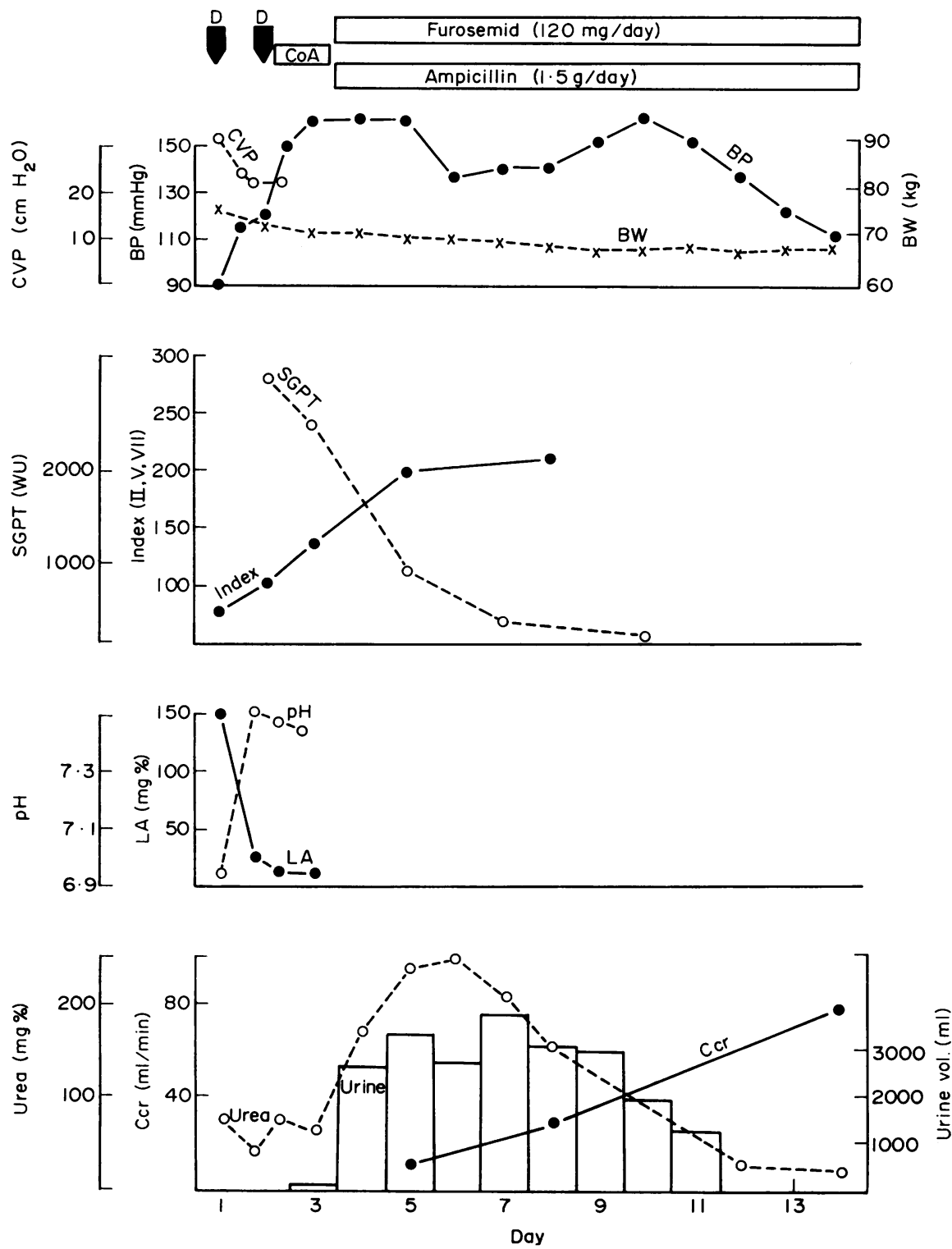

FIG. 3. Patient A. H. P., body weight, circulatory, hepatic and renal features during and after haemodialysis (D) and administration of cofactor (CoA). CVP, central venous pressure; BP, systolic blood pressure; BW, body weight; LA, lactic acid; Ccr, creatinine clearance.

hepatic failure, for it is capable of correcting severe metabolic disorders arising from hepatic insufficiency.

An increase in blood lactate is a regular feature of severe acute hepatic failure, and sodium retention is also commonly present in this condition (Colombi, 1969), due to secondary aldosteronism and/or renal failure. Lactic acidosis can be corrected by the administration of sodium bicarbonate or THAM, unless sodium retention precludes further expansion of the extracellular volume. In these circumstances haemodialysis offers a method of correcting the lactic acidosis without the danger of sodium or volume overload, both by buffering the $\mathrm{H}^{+}$ions and also by the removal of lactate.

The underlying cause of hepatic and renal 
insufficiency in the case described here is not clear. Hepatic insufficiency and right heart failure preceded both decrease of BP and renal insufficiency. Moreover histology of the liver biopsy specimen was consistent with a cardiovascular origin and seemed to exclude viral or drug-induced hepatitis. Furthermore Weil's disease, mushroom poisoning or $\mathrm{CCl}_{4}$ poisoning and pancreatitis were all excluded either by the history or laboratory investigations. Vitamin B complex was given initially before thiamine deficiency could be proved.

\section{References}

ColombI, A. (1969) Early diagnosis of fatal hepatitis. Digestion, 3, 145.
Ewy, G.A., Pabico, R.C., Maher, J.F. \& Mintz, D.H. (1963) Lactate acidosis associated with phenformin therapy and localized tissue hypoxia. Annals of Internal Medicine, $59,878$.

Maher, J.F. \& Schreiner, G.E. (1967) The dialysis of poisons and drugs. Transactions of the American Society of Artificial and Internal Organs, 13, 384.

Thölen, H., Colombi, A., DuCkert, F., Huber, F., Müller, H.R. \& BigleR, F. (1966) Effects of a treatment with CoA; lipoic acid, diphosphopyridine nucleotide and cocarboxylase on endogenous hepatic coma. Helvetica medica Acta, 33, 492.

Trey, C., Burns, D.G. \& SAunders, S.J. (1966) Treatment of hepatic coma by exchange blood transfusions. New England Journal of Medicine, 274, 473.

Westervelt, F.B., Jr, HoRnbaker, J.H., OWen J.A. \& GoRsUCH, T.L. (1966) Lactic acidosis. Virginia Medical Monthly, 93, 251.

\title{
Pneumatic rupture of colon
}

\author{
RAJ KuMAR \\ F.R.C.S. (Ed. \& Eng.) \\ T. R. RowE \\ M.S. \\ P. B. Dave \\ M.B.,B.S. \\ Department of Surgery, Main Hospital, Bhilai Steel Plant, Bhilai, India
}

PNeumatic rupture of colon is a rare type of industrial accident, first reported by Stone in 1904. Since then there have been a few reports. The classical paper of Wyllys Andrews (1911) gives a vivid description of this injury. Invariably, this accident is the result of a practical joke, when the nozzle of a compressed-air hose is directed at the anal region of the victim. The rarity of the injury has prompted us to report the following case.

\section{Case Report}

S.L., 40-year-old male, working in the blast furnace of Bhilai Steel Plant, was admitted as an emergency on the afternoon of 18 June, 1970, complaining of severe abdominal pain and difficulty in breathing. About an hour earlier, while at work in the plant, two of his co-workers held him firmly and directed the outflow nozzle from a compressed-air pipeline towards his anal region and opened the release valve. He suddenly felt a sensation of 'blowing up' with acute abdominal pain and diffculty in breathing.

On examination, he was conscious but had agonizing abdominal pain. The respiratory rate was $45 / \mathrm{min}$, with very shallow, thoracic type of breathing. Pulse was $120 / \mathrm{min}$ and B.P. $90 / 60 \mathrm{~mm} \mathrm{Hg}$ The most striking feature was a grossly distended abdomen. On palpation there was acute generalized tenderness with board-like rigidity of abdominal wall. The percussion note was tympanitic and liver dullness obliterated. No free fluid was detected. Bowel sounds were absent. Examination of the perineum did not show any external injury. Rectal examination did not reveal any laceration or perforation in the anal canal or rectum. Some blood was noticed on the examining finger.

A clinical diagnosis of pneumatic rupture of colon was made.

Straight X-ray abdomen in erect position showed extensive pneumoperitoneum with compression and clear visualization of liver, spleen and gall bladder.

Operation. After initial resuscitation, a laparotomy was carried out through a lower left paramedian incision. As soon as a small opening was made in the peritoneum, the air whistled out and the distended abdomen collapsed like a pricked balloon. Concomitant with this deflation, the anaesthetist reported sudden improvement in the respiration and 